\title{
Las estrategias de la inclusión
}

\author{
Juan Soto Ramírez*
}

\author{
Categoría: Comunicado \\ Fecha de recepción: 28 de mayo de 2012 \\ Fecha de aprobación: 28 de junio de 2012
}

\begin{abstract}
Resumen
El tema de la exclusión ha sido demasiado discutido en disciplinas como la sociología y la antropología social. Incluso en la psicología social la temática ha nutrido bastantes investigaciones. Como tópico ha dado lugar a innumerables reflexiones de grandes pensadores e intelectuales. Frente a las diversas facetas que ha adquirido la exclusión en el mundo contemporáneo, paulatinamente se han gestado diversos modos de inclusión más allá de la oposición material y simbólica que son dignos de ser analizados y discutidos. En este texto se discuten sólo tres: el mundo de las imitaciones, la conexión multifrénica y el entretenimiento de bajo nivel. Con el afán de apropiarse de una subjetividad que les ha sido negada, los 'desafiliados' de diversos sistemas simbólicos han optado por generar estrategias de inclusión en el ámbito de la vida cotidiana y son dignas no sólo de ser analizadas sino de ser discutidas. A lo largo de todo el texto se llama la atención sobre los heurísticos que apuntalan las formas contemporáneas del consumo.
\end{abstract}

Palabras clave: Exclusión, Estrategias, Consumo, Entretenimiento, subjetividad, redes sociales

\begin{abstract}
The issue of exclusion has been overly discussed in disciplines such as sociology and social anthropology. Even in the social psychology, it has drawn considerable research interest. As a topic has led to countless thoughts of great thinkers and intellectuals. Given the different facets that exclusion has acquired the exclusion in the contemporary world, various modes have been increasingly developed beyond the material and symbolic opposition, which are worthy of being analyzed and discussed. In this paper, we discuss only three: the world of imitations, the 'multifrenica' connection and low level entertainment. In an attempt to seize a subjectivity that has been denied, the 'unaffiliated' from various symbol systems have chosen to generate strategies for inclusion in the scope of everyday life and are worthy not only be analyzed but to be discussed. Throughout all texts, it is emphasized the heuristics that underpin contemporary forms of consumption.
\end{abstract}

Keywords: Exclusion, Strategies, Consumption, Entertainment, subjectivity, Social Networks

* Profesor Titular C de Tiempo Completo de la Universidad Autónoma Metropolitana (UAM), Unidad Iztapalapa, México, D.F. Licenciado en Psicología Social por la Universidad Autónoma Metropolitana (UAM), Unidad Iztapalapa. Maestro en Psicología Social por la Facultad de Psicología de la Universidad Nacional Autónoma de México (UNAM). Doctor en Antropología Social por la Escuela Nacional de Antropología e Historia (ENAH), juansotoram@hotmail.com 


\section{Introducción}

Las formas que ha adoptado la exclusión social no sólo son diversas sino evidentes en muchos ámbitos de la vida cotidiana. Diferentes disciplinas sociales se han encargado de reflexionar y discutir al respecto, pero han dejado de lado dos cuestiones que parecen importantes. La primera es que la exclusión se encuentra ligada a la inclusión. Forman parte de un continuum. Están mutuamente implicadas. La segunda es que tradicionalmente la exclusión se ha estudiado en demasía y, por obvias razones, no se ha puesto atención en los modos en que los 'desafiliados' de los sistemas se resisten a ser excluidos y, gracias a ello, generan estrategias para no quedar fuera de estos últimos.

Poner atención a dichas estrategias de inclusión nos permite conocer la manera en que las masas, como las olas, van de un lado a otro. $\mathrm{Y}$ los dominios por excelencia para analizar esto son, sin lugar a dudas, los del consumo, el ocio y el entretenimiento. En ellos es donde se ve reflejado el pensamiento colectivo. Es donde se puede mirar con lujo de detalle, por ejemplo, que la cultura ha perdido profundidad y paulatinamente se ha trivializado. En el ámbito del consumo es más que evidente cómo la inclusión de unos pocos va generando desafiliaciones masivas, pero a su vez esto trae consigo fenómenos culturales dignos de ser analizados.

La idea central de este texto es que frente a los procesos de desafiliación, provocados por los despidos masivos, el endeudamiento a gran escala, el debilitamiento de los sistemas políticos y la degradación de la calidad de vida, entre otros, a nivel de la vida cotidiana, a 'ras de suelo', se van generando no sólo formas de resistencia cultural y de sobrevivencia económica sino también estrategias de inclusión para no quedar fuera de los sistemas materiales y simbólicos que alimentan el funcionamiento de la cultura.

Y aunque si se pone la atención debida seguramente se descubrirán muchas más, en este escrito sólo se analizarán tres. El mundo de las imitaciones, la conexión multifrénica y el entrete- 
nimiento de bajo nivel. Otra de las ideas centrales es que diversas prácticas culturales que apuntalan estos tres fenómenos, son un conjunto de heurísticos. Es el 'pensamiento débil' lo que permite que el razonamiento colectivo funcione a través de razonamientos simples, pero eficientes. Sin embargo, es preciso señalar que para arribar a la discusión de estos tres puntos, primero es necesario retomar ciertos aspectos relevantes sobre la exclusión en el marco de la discusión sociológica. A saber: el acceso desigual a los sistemas, la excesiva monetarización de los problemas y la aparición de nuevas amenazas y riesgos. Sin estos tres fenómenos, sería difícil comprender el modo en que aparecen estrategias colectivas de apropiación, material y simbólica, que le permiten a la gente obtener satisfactores a nivel subjetivo para sentirse incluida.

\section{Consumo y exclusión}

Es un lugar común en distintas disciplinas sociales hablar de la exclusión. Es un tema recurrente en Sociología, Antropología Social e incluso en la Psicología Social. Bajo la forma sociológica de la marginación, la exclusión, como tema de investigación, incentivó la escritura de cientos o miles de páginas que se dividieron, más o menos, entre estudios académicos serios y consignas panfletarias disfrazadas de investigación social.

Como haya sido, cualquiera puede recordar la amplia obra del Profesor Alain Touraine e identificar cómo la marginación ha sido uno de los temas centrales y recurrentes en sus reflexiones. Para Touraine (2011), el retroceso social, no tanto el político, implica la defensa de las libertades que se habían ganado tiempo atrás. Dos aspectos son centrales en sus disertaciones: a) el que tiene que ver con la oposición entre los dueños del dinero versus los ciudadanos comunes, y b) el que tiene que ver con la reivindicación ciudadana (ya sea por la vía de la participación política u otros medios) de cara a la defensa de los derechos universales (a través de la lucha social, por ejemplo). 
La crisis económica, mal nombrada por muchos 'desaceleración', ha generado, en el sentido de la reflexión de Touraine, cada vez más 'desafiliados' y ha producido un, digámoslo así, adelgazamiento de las clases medias. Los despidos masivos, el endeudamiento a gran escala, el debilitamiento de los sistemas políticos y la degradación de la calidad de vida, entre otros, son algunos de los principales obstáculos que deben enfrentarse a diario y sirven como directrices de lo que bien podríamos denominar nuevas estrategias de sobrevivencia. Es así que las formas de exclusión social parecen agudizarse en dos ámbitos de fácil identificación. En el dominio de la salud, la educación y la previsión, así como en el terreno del acceso a bienes y servicios (Lechner, 1998: 187).

En el campo de la salud y la previsión social es fácil encontrar numerosos casos alarmantes de personas que no cuentan con los beneficios de los sistemas sanitarios. Bien porque se han ido privatizando, bien porque el ingreso a este sistema se encuentra condicionado por la incorporación a otro que es el del trabajo. Es decir, el arribo al mundo laboral, de una u otra forma, garantiza la afiliación a los servicios de salud, pero la crisis económica que conlleva a los despidos masivos produce, a su vez, desafiliados de ambos dominios: el de salud y el del trabajo.

Debemos decir que así como las grandes crisis económicas y financieras tienen su debido impacto en los campos de salud y la previsión, también lo tienen en el de la educación. Según Norbert Lechner (1998: 187-191), las deficiencias de los sistemas provocan un sentimiento de desvalidez e impotencia gracias a tres factores. El primero está dado por el acceso desigual a los sistemas funcionales (que son la educación, la salud y la previsión). Y es preciso resaltar que independientemente de que la incorporación a dichos sistemas se encuentre condicionada, además, haya que pagar por ello. El nivel socioeconómico juega un papel decisivo en la afiliación a dichos servicios. Podemos decir pues que nuestra sociedad está caracterizada por la marcada desigualdad en 
cuanto a la adhesión a los sistemas funcionales, muy a pesar de los servicios públicos existentes, tanto educativos como sanitarios (que, a su vez, deben enfrentarse a diario con los problemas de los recortes presupuestales y la corrupción, por mencionar sólo dos casos).

El segundo factor del que habló Lechner fue el de la excesiva monetarización de los problemas que, grosso modo, termina por excluir a las personas de escasos recursos económicos de los servicios básicos. Dicho factor tiene un desenlace trágico pues desemboca en la privatización de algunos servicios públicos básicos y trata, de forma sutil y descarada, de acabar con ellos (por no decir que intenta exterminarlos). La educación y la salud pública, tanto en México como en los países de América Latina, padecen los embates directos del estrangulamiento financiero. Fenómeno típico del neoliberalismo. Por un lado se privatizan ciertos servicios que deberían ser públicos y, por otro, se emprenden campañas de recortes presupuestales injustificados. Y así la población desarrolla un sentimiento de indefensión, es decir, no se siente protegida ni respetada.

De acuerdo con Lechner (1998: 188), “los sentimientos de dignidad, identificación e integración que generaba anteriormente el trabajo", se ven sumamente debilitados en la nueva organización de las empresas. Enfermarse se traduce en un verdadero dilema financiero. Caer enfermo no sólo implica gastar dinero sino que es caro. La salud se convierte en una inversión y un negocio, tanto que las compañías cuentan con seguros de gastos médicos e incluso accidentes. En palabras de Touraine (1997: 188), la vida social, al degradarse, se convierte en mercado. Es decir "la sociedad de producción se transformó en sociedad de mercado" (Touraine, 1997: 91). Estos y otros ejemplos ponen en evidencia la ruptura existente del vínculo entre la sociedad y la cultura, mientras que "la proletarización cultural de las masas sometidas a los mensajes difundidos por los medios ya sólo deja frente a frente a mercados triunfantes y comunidades agresivas" (Touraine, 1997: 92). 
El tercer factor del cual habló Touraine fue el de la existencia de un nuevo tipo de amenazas. Es decir, la sociedad se ha convertido en productora de riesgos a tal grado en que ella misma se ha transformado en un espacio peligroso. Años atrás, antes de Touraine, U. Beck (1986), había reflexionado ya al respecto. De acuerdo con Beck, el accidente nuclear de Chernobyl modificó la percepción del riesgo a escala mundial. La seguridad, entonces, pasó a ocupar un lugar que no tenía en la sociedad. No obstante, la oposición para Beck no está dada entre los mensajes difundidos por los medios y las comunidades agresivas sino en la forma en que se reparten riesgos entre ricos y pobres debido a la fractura de la estratificación social anterior.

El origen del riesgo para Beck es propio de la sociedad de la riqueza. El consumo excesivo se vuelve dañino y la participación es sustituida por otro proceso social que es la protección. Las 'orgías del consumo' y la 'embriaguez por el consumo', tal como las ha denominado Lipovetsky (2006: 198), se han instalado como un modo de vida contemporáneo. Estas prácticas culturales asociadas a los 'excesos' han devenido riesgosas por sí mismas. No sólo porque escapan al cálculo racional de sus efectos sino porque se diluyen en el mero presentismo. Lo sabemos bien, "los temas de la seguridad y la salud inundan la vida cotidiana" (Lipovetsky, 2006: 199).

En este sentido, la defensa de las dinámicas de la exclusión, ha apuntado Lechner (1998: 189), al menos subjetivamente, implica un repliegue hacia la esfera de lo individual. Y coincide con Lipovetsky (2006: 200), quizá sin quererlo, quien, dicho sea de paso, ha sostenido que el repliegue se manifiesta en los pequeños grupos. El zapping, por ejemplo, se ha convertido en una especie de 'ritual' que materializa la utopía del control en la intimidad mientras que el shopping, de carácter público, cristaliza el consumo excesivo apartado de todo cálculo racional. A nivel de vida cotidiana encontramos entonces un sinfín de imágenes que hacen evidente que la desafiliación institucional y la exclusión social 
promueven, sin quererlo, su contraparte. La desafiliación institucional promoviendo la afiliación simbólica a la sociedad.

Hoy más que nunca, el consumo parece haber atravesado ya por una fase de naturalización drástica. Cualquier consumible, desde el más insignificante hasta el más ostentoso, desde el menos lujoso hasta el más opulento, lleva detrás el sello de una firma comercial. Verdú (2003: 123) lo ha ejemplificado de la siguiente manera: "ya no decimos que usamos un pañuelo de papel sino un Kleenex, no tomamos cualquier café sino un Nescafé" y así sucesivamente. Los ejemplos sobran, en vez de solicitar un producto sólo diga la marca, incluso puede combinar algunas, "añejo con coca cola y peñafiel" en vez de solicitar al mesero un ron con refresco de cola y agua mineral.

El miedo a la exclusión "está estrechamente vinculado a un rasgo fundamental de la sociedad actual: la creciente autonomía de las lógicas funcionales" (Lechner, 1998: 189). En efecto, las lógicas de los sistemas, basadas en sinsentidos, se erigen en los verdaderos poderes fácticos. Esto explica en parte la existencia de heurísticos que otorgan significado y justifican buena parte de lo que ocurre en la vida cotidiana. En el dominio del consumo, dichos heurísticos podrían identificarse en expresiones como las siguientes: "lo barato sale caro"; "si es caro es bueno"; etc. Mientras tanto, del otro lado de la cara de la moneda, encontramos que esta lógica del sinsentido también la podemos hallar en la arbitrariedad de las reglas y normas sociales, como en el hecho de no vender alcohol cuando hay procesos electorales o no venderlo sino hasta determinada hora, que se fija por determinaciones políticas, económicas o jurídicas.

Los razonamientos basados en heurísticos tienen un modo de circulación y reproducción eficiente ya que son parte esencial de los procesos de socialización y porque apuntalan las creencias o el pensamiento colectivo. Si bien es cierto que mientras las lógicas de los sistemas sociales, políticos y económicos parecen imponerse en un sentido vertical, de manera sutilmente autoritaria, frente 
a ellas aparecen formas de contraargumentación y oposición que conducen al cuestionamiento, a la revuelta y a la resistencia, pero debemos tomar en cuenta que "ni los sujetos pueden disponer libremente de las lógicas funcionales, ni los sistemas logran apropiarse completamente de la subjetividad" (Lechner, 1998: 190).

Lo anterior podría explicar la manera en que han cambiado las formas del consumo. Éste se ha vuelto más emocional "hemos pasado de una lógica centrada en la oferta, la creación y el creador, a una lógica que integra la demanda, la competencia, las necesidades del mercado y las de los consumidores" (Roux, 2003: 107). El consumo ha pasado a ser una forma de entretenimiento, se ha afirmado como algo legítimo e incluso se encuentra asociado al ejercicio de la libertad personal. Miles de personas alrededor del mundo están convencidas de que el shopping contrarresta los efectos de la depresión.

Por su parte, el gasto dispendioso o fuera del presupuesto habitual se considera un lujo legítimo entre muchas personas, quienes lo justifican a través de una lógica que conjunta esfuerzo y recompensa, desgaste (físico y emocional) y retribución (material y simbólica). Es obvio que la retribución y la recompensa van incluidas en la adquisición del bien. Es decir, son el plus emocional que su adquisición conlleva. Los heurísticos que hacen evidente este proceso son los siguientes: "si tanto trabajas, cómpratelo"; "si tanto trabajas y te esfuerzas, te lo mereces".

Podemos ver pues que frente a la 'subjetividad negada' se despliegan estrategias de afiliación que corren paralelas a las formas de resistencia social. El trabajo informal y el free lance serían dos ejemplos de ello y si bien operan bajo lógicas distintas, podríamos considerarlas como estrategias de incorporación (materiales y simbólicas), al mundo laboral. Es pertinente destacar que no en todos los casos la desafiliación laboral sea siempre forzada. En muchos casos ésta es razonada y se erige como una forma alternativa a la precarización del empleo y las condiciones de trabajo (el heurístico que apuntala dicha estrategia es el de 
"sé dueño de tu tiempo"; "sé tu propio jefe"). Pero es claro que la desafiliación del mundo laboral no se da al ciento por ciento. Tanto el free lance como el denominado trabajo informal siguen dependiendo, indirectamente, del mundo laboral.

Vistas así las cosas, podríamos afirmar que la exclusión como tema de reflexión sociológica sigue siendo interesante, pero deberíamos señalar que las estrategias de inclusión que se despliegan como modo de vida o como formas de apropiación material y simbólica también lo son y se les ha pensado poco. Y aunque hay diversas formas, sólo analizaremos tres.

\section{El mundo de las imitaciones}

Frente al consumo opulento, frente al consumo ostentoso y el lujo inalcanzable, se yergue todo un mercado 'alternativo'. El de la copia o las imitaciones. Los duplicados juegan un papel muy importante en la desarticulación de la funcionalidad y satisfacción emocional que brinda el original. El heurístico es: "lo mismo, pero más barato". Es cierto "el consumo de la 'imitación' es una especie de bluff [...] que engaña sobre todo al que lo practica, primer interesado en tomar la copia por el original y el relumbrón por lo auténtico, a la manera de los compradores de 'imitaciones', de saldos o de ocasión, que quieren convencerse de que 'es más barato y hace el mismo efecto'" (Bourdieu, 1979: 327).

El éxito de las copias sólo cobra sentido en las sociedades que valoran no sólo la diferenciación o la individualización a través del consumo y la adquisición de bienes materiales, sino donde el 'prestigio asociado a la marca' ha jugado un papel clave en los procesos de distinción social. Es decir, donde se ha hecho del consumo una forma de diferenciación y reconocimiento social. Esto resulta ser un tanto paradójico pues el mundo de las imitaciones triunfa justo donde a las copias se les desprecia. Es decir, donde los originales están sobrevalorados y las copias ofrecen al consumidor un sustituto emocional que también brinda el original. Los 
duplicados son pues una especie de 'objetos placebo' que brindan a quienes las adquieren un sustituto subjetivo que les permite, al menos en la ficción, compensar la desigualdad material con el beneficio emocional. "Para desmarcarse con respecto a quienes están desprovistos de ella [la copia], la pretensión inspira la adquisición, que trivializa de por sí, las propiedades hasta entonces más distintivas, y contribuye con ello a sostener continuamente la tensión del mercado de bienes simbólicos, obligando a los poseedores de las propiedades a la afirmación de su singularidad" (Bourdieu, 1979: 249).

El consumo emocional implica que las necesidades de los consumidores están incluidas o son tomadas en cuenta tanto en el 'diseño' de los productos como en las formas en que la publicidad presenta a dichos objetos. La publicidad ya no sólo define lo que se consume sino bajo qué términos y condiciones. En todo momento podemos hallar una tentativa de proyectar la identidad de los consumidores en ciertos rasgos característicos de los productos. "La clientela de los años ochenta consumía marcas de lujo 'cueste lo que cueste', la de los años noventa ya no quería comprar 'a cualquier precio', la de la década del 2000 supedita sus afinidades e identificaciones afectivas a las marcas que saben proyectar su identidad y reinterpretarla de manera creativa y coherente, ciñéndose a la época o en otro universo" (Verdú, 2003: 110).

Las formas que ha adoptado el consumo han permitido que la distinción social sea evidente en distintas categorías (Verdú, 2003: 73): realista (el original versus la imitación); género (lo masculino versus lo femenino); temporal (lo actual versus lo fuera de moda); etc. Las posibilidades parecen ser infinitas. Las marcas, más que tratar de vender prestigio al día de hoy, más bien intentan difundir estilos de vida asociados a los productos. Y el mundo de las imitaciones es uno de los mejores ejemplos de ello. Desde el arte hasta la cocina. Desde la salud hasta la moda. Etcétera. Las imitaciones ofrecen a los excluidos del consumo ostentoso $\mathrm{u}$ 
opulento la posibilidad de acceder a él de manera simbólica bajo la ilusión de que la réplica provee, aunque sea de manera ilusoria, el mismo bienestar emocional que el original.

\section{La conexión multifrénica}

Fue Gergen $(1991,37)$ quien utilizó, de manera lúdica, el concepto multifrenia para referirse a "la fragmentación y colonización de la experiencia del yo" en relación con el cambio tecnológico y la forma en que "va penetrando cada vez más en nuestras interpretaciones y relaciones". El concepto de conexión multifrénica no sólo se centra en la forma en que "la saturación social acarrea un menoscabo general de la premisa sobre la existencia de un yo verdadero y reconocible" (Gergen, 1991: 37), sino también en el hecho de que las transformaciones tecnológicas han multiplicado de manera sorprendente nuestras posibilidades de conexión y localización.

Lo paradójico de la sobrelocalización y la multiconexión es que frente a tantos millones de usuarios conectados a las denominadas redes sociales es fácil sentirse solo. La conexión multifrénica permite, entre otras cosas, no sólo estar en red sino permanecer conectado todo el tiempo. Ya no es necesario encender una computadora y permanecer con los ojos pegados en la pantalla en espera de notificaciones o nuevas actualizaciones para intercambiar información en forma de mensajes o simples clics transformándose en "me gusta". Las imágenes de un grupo de personas sentadas a la misma mesa actualizando sus estados, indicando dónde se encuentran o haciendo llamadas al mismo tiempo ya no son extrañas para ninguno de nosotros. Los cambios tecnológicos se han inmiscuido en nuestras formas de relación.

Oguibe (2002: 135) ha señalado que en el mundo contemporáneo ha surgido una divisoria digital "entre los que tienen derecho a estar dentro de la red y así pueden participar de sus numerosas ventajas, y los que no pueden llenar los requisitos de la conectivi- 
dad". Pero ha dicho también, muy atinadamente, que la cuestión de la conectividad y la no conectividad no es algo que tenga que ver con la pertenencia social, como se ha pensado durante mucho tiempo. "En las naciones más industrializadas hay un gran número de personas cuya improbabilidad de que simplemente se conecten es tan grande como la de muchos en las regiones menos desarrolladas del mundo, un hecho que corroboran cada vez más las estadísticas que están apareciendo" (Oguibe, 2002: 137).

En efecto, "los contextos social y material de la no conectividad trascienden el delineamiento geopolítico tradicional y pueden ser hallados con la misma facilidad en las naciones altamente industrializadas en el llamado Tercer Mundo. En otras palabras, la cartografía de los no conectados o [del] Tercer Mundo Digital es, en lo fundamental, una cartografía de clase que trasciende la nación (Oguibe, 2002: 137). Es una falacia seguir pensando que los conectados son los únicos representantes de nuestro momento histórico. Y también lo es seguir pensando que las revoluciones se cocinan primero en las redes sociales. A partir de lo anterior no se puede subestimar el papel y el poder que han tenido estas últimas en años recientes en materia de difusión, pero de ahí a creer en la online revolution hay un abismo insoslayable. Los casos de wikileaks y de anonymous no sólo son de digno reconocimiento sino bastante ilustrativos, pero de ahí a creer que la revolución es posible circulando ideas burguesas disfrazadas de retórica incendiaria en las redes sociales es demasiado absurdo.

La red ofrece a los usuarios, frente a los 'desiertos repletos de gente', la satisfacción psicológica de saber que otro, simplemente, también está allí. Razón por la cual podemos entender que los conectados no siempre se comuniquen entre sí. Sólo se monitorean para saber si siguen ahí. La conectividad implica pues conexión global frente a desconexión local. Sin embargo, para los no conectados, por contradictorio que parezca, los conectados, muchas veces, representan un verdadero peligro. "En ausencia de las voces de éstas, sitúa o fabrica sin demora voces dentro que asumen la autoridad de hablar por el Otro, puesto que, muy a menudo, no 
escasean los grupos e individuos que aprovecharían la ocasión para designarse y delegarse a sí mismos como representantes de los ausentes. Hoy día tales individuos y grupos abundan por los capilares y nudos de la Red: luchadores solitarios y grupos de presión temporales, organizaciones de amigos preocupados y revolucionarios auto designados, figuras mesiánicas que vienen al rescate de los desvalidos, anarquistas en busca de preocupaciones y activistas remanentes de causas fracasadas, ansiosos de hallar nuevas causas que pudieran mitigar su pasión de vivir" (Oguibe, 2002: 140).

De cara a los cambios tecnológicos, ha aparecido un continuum en cuyos extremos encontramos, por un lado, la 'tecnofilia' y, por otro, la 'tecnofobia'. Sea por miedo, por aversión o por otras causas, frente a las actitudes 'tecnofílicas' encontramos otras que ofrecen un contrasentido. Mientras unos (los tecnófilos), se esfuerzan incansablemente por permanecer conectados a la red, muchos otros (los tecnófobos), tratan de evitar a toda costa alguna relación con las denominadas tecnologías de la información y la comunicación, así como con los productos tecnológicos de última generación. Los tecnófobos son como una nueva clase de hippies o una especie de posthippies que se resisten, por ejemplo, a comprar un teléfono celular o a habilitar su perfil de Facebook como una forma de protesta simbólica o bien como una forma de diferenciarse y de reivindicar su individualidad frente a los comportamientos colectivos (no obstante las actitudes anti tecnología están fundamentadas en heurísticos del tipo: "la tecnología esclaviza"; "la tecnología deshumaniza"). Pero formas de distinción también las encontramos entre los 'tecnófilos'. Éstas remiten a la superflua dualidad de ¿Twitter o Facebook? Que vista así podría remitir a dos partidos políticos con un gran número de seguidores en todo el mundo.

Los disidentes del mundo digital, quienes también podrían ser como una especie de postpunks, también defienden su derecho a no ser 'etiquetados en red', por ejemplo. Algunos otros, de configuración ideológica un tanto más extraña, utilizan correo 
electrónico, pero se niegan a abrir una cuenta en Facebook. Es muy probable que estos seres anti tecnología no se nieguen a musicalizar su vida cotidiana y pasen un buen número de horas frente a la televisión o la computadora. Se podrán negar a las redes sociales, pero no a la utilización de las nuevas tecnologías. Sean éstas de alto o bajo nivel.

Todo parece apuntar a que esta conexión multifrénica permanente no está naturalizada socialmente como sí lo está la utilización de los teléfonos celulares y los reproductores de dvd, por ejemplo. Es muy probable también que estos hippies del mundo contemporáneo gocen de los efectos secundarios de la radio (Sartori, 1997: 35), musicalizando sus prácticas sexuales aunque se resistan a conectarse en red. La gran paradoja de todo esto es que independientemente de que uno renuncie a la multiconexión, sea por analfabetismo tecnológico o por animadversión, no se puede renunciar al uso de los productos tecnológicos por mucho que uno se decida a escalar una montaña para escapar del resto del mundo.

\section{El entretenimiento de bajo nivel}

Delante de lo que podríamos denominar 'entretenimiento culto', aparecen ahora diversas formas de entretenimiento cuya calidad es nula o casi nula. Verdú (2005: 21), lo ha dicho de esta forma: "la sociedad de consumo tiene como misión proveer de placeres sin tregua y como destino esencial la diversión hasta morir. La cultura de consumo no ha prosperado con la penitencia del trabajo, sino con la fiesta sin fin. Con una cultura sin sacramentos, donde los autores del cine, la radio, de la escritura, del telefilme proporcionan distracciones laicas, superficiales, dirigidas al entretenimiento y al sentir superficial". La cultura ha perdido así, profundidad.

Las célebres nulidades se convierten, rápidamente, en una 'cultura sin culto', en los centros de atención para millones de desafiliados a la 'cultura culta'. En palabras de Mark Dery (1999), 
los años noventa tuvieron una cualidad 'oscuramente cómica': para él fue una década cautivada por célebre nulidades y el elenco del Zippergate cuya estrella fue Monica Lewinsky. Una cultura sin culto no es aquella que no lee sino aquella precisamente que rinde tributo a las historias donde los protagonistas son, por ejemplo, magos y brujos movidos por los hilos de una situación narrativa arquetípica (Eco, 2006: 303).

Sobra decir que la tediosa e insulsa historia de Harry Potter no ofrece mucho a sus fanáticos, pero desgraciadamente no son capaces de darse cuenta de ello. Sin miramientos podemos afirmar que "sin Harry Potter la literatura no pierde nada, pero sin el libro sus no lectores se pierden la participación en la actualidad" (Verdú, 2005: 35). Y esta última es precisamente la forma de contrarrestar la desafiliación de la 'cultura culta'. Asumiendo que devorar best sellers (que es más o menos equivalente a leer lo que sea) es una actividad culta, sobre todo si una buena cantidad de personas (miles o millones), están leyendo el mismo libro. Un lector promedio es incapaz, claro está, de distinguir entre un buen y un mal libro. Sabemos que en muchos países se deposita un voto de confianza en una actividad tan sensata como la de leer, pero se hace muy poco por enseñar a esos lectores a diferenciar entre un libro de calidad y uno que no la tiene. Leer es sensato, pero no todos los libros ofrecen el mismo nivel de excelencia.

Es cierto, leyendo best sellers no se alcanza la erudición. El alcance de estos libros no va más allá de las charlas de café. Pero lo que dejan a sus lectores es simplemente la satisfacción emocional de haberlos leído. Una de las grandes contradicciones es que cada año se sigan publicando más libros y los lectores sean cada vez menos (Verdú, 2005: 35). En una cultura sin culto, es fácil ser presa de las orgías de los mass media. Las series de televisión, por ejemplo, desde las de escritores o médicos ebrios hasta las de un puñado de personas que aparecen por causas inverosímiles en una isla que aparece y desaparece, se convierten en el suceso conversacional de moda y de los programas de entretenimiento. 
No verlos o no saber de ellos lo deja a uno fuera de innumerables conversaciones triviales y sin sentido. Tomar distancia con las orgías televisivas lo sitúa a uno lejos del entendimiento de los chistes que se puedan hacer en torno a ello.

El entretenimiento de bajo nivel, que está a la orden del día en cualquier sociedad contemporánea, es de fácil reinversión y evita, a toda costa, la reflexión profunda o la lentitud. Podríamos decir que, en este sentido, el divertimento se ha vuelto más eficiente, pero que las consecuencias de esto son desastrosas pues ha adquirido un carácter cada vez más trivial. Sobra decir que esto es una condición general de las ofertas de la industria del ocio. Lo vemos en el cine, la música, el teatro, la televisión, el internet, la literatura, pero sobre todo en el orden de reproducción por excelencia de lo social que son las conversaciones cotidianas. La gente evita hablar de cosas profundas, prefiere el consumo eficiente o de fácil reinversión que versa sobre las trivialidades de la vida.

Frente al resquebrajamiento de la cultura culta se ha erigido una industria cultural de lo superfluo que si bien refleja y dicta los patrones de consumo de la derrama económica, se presenta como legítima apelando a la masificación del consumo de determinados productos (el heurístico aquí sería que "si lo consume la mayoría hay que consumirlo también"; "si 10 millones de personas se ríen con eso, es que definitivamente es divertido").

\section{Conclusiones}

El acceso desigual a los distintos sistemas de la sociedad, la excesiva monetarización de los problemas y la aparición de nuevas amenazas y riesgos ha propiciado, sin quererlo, el surgimiento de fenómenos culturales y sociales que, para fines de análisis, se han llamado en este trabajo 'estrategias de inclusión'. Cabe mencionar que las señaladas aquí no son precisamente las únicas. Seguramente el lector podría haber descubierto ya muchas más. 
Sólo por mencionar algunos otros ejemplos con el afán de no caer en la repetición, se podría decir que a pesar de tanta revolución científica y tecnológica, el pensamiento mágico, icono cultural de la Edad Media, ha prevalecido hasta nuestros días. No se ha extinguido. Y con él, una pléyade de fenómenos culturales se puede vislumbrar. En términos muy generales, podemos decir que Occidente ha entrado en un proceso acelerado de 'orientalización'. Lo que explica el éxito del reiki, el yoga, el feng shui, etc.

De forma paralela, la sociedad ha entrado en un severo proceso de medicalización. Como práctica, la automedicación se ha extendido mientras que la industria médica ha hecho de la salud un verdadero mercado. Así, encontramos otra oposición. Mientras la industria insiste en medicalizar los problemas, las 'terapias alternativas' insisten en desacreditar a la ciencia médica. Y es en los terrenos de estas últimas que encontramos, también, formas a través de las cuales la gente intenta incluirse por la vía de la desacreditación de los discursos médicos institucionales.

Sólo por poner el último ejemplo, quizá el más divertido de todos, sea el del sexo desenfrenado. Gracias a la industrialización del sexo y a que éste se ha convertido en un gran negocio, es que podemos considerarlo el último recoveco de la defensa de la identidad, no sin dejar de mencionar que esto tiene su lado oscuro en los dominios de la prostitución y la pornografía infantil por poner dos casos de fácil identificación. No obstante, en el lado amable, ha devenido una estrategia de inclusión en la medida en que se ha convertido en una forma de entretenimiento colectivo.

\section{Bibliografía}

Beck, U. (1986): La sociedad del riesgo. Hacia una nueva modernidad, Barcelona, Paidós, 1998.

Bourdieu, P. (1979): La distinción. Criterio y bases sociales del gusto, Madrid, Taurus, 1991.

Dery, M. (1999): El manicomio piroténcnico: un sueño norteamericano envuelto en llamas. Disponible en: http://www.dios.com. 
ar/notas1/creencias/conspiranoia/pirotecn/piro-manicomio.htm

Gergen, K. (1991): El yo saturado, Barcelona, Paidós, 1992.

Lechner, N. (1998): “Nuestros miedos" en Pefiles Latinoamericanos, México, Facultad Latinoamericana de Ciencias Sociales, año 7, núm. 13, diciembre, 179-198.

Lipovetsky, G. (2006): La felicidad paradójica, Barcelona, Anagrama, 2007.

y Roux, E. (2003): El lujo eterno, Barcelona, Anagrama, 2004.

Oguibe, O. (2002): "La conectividad y el mundo de los no conectados" en Criterios, La Habana, núm. 33, cuarta época, 135-149.

Sartori, G. (1997): Homo videns. La sociedad teledirigida, Madrid, Taurus, 2001.

Touraine, A. (2011): Después de la crisis. Por un futuro sin marginación, Barcelona, Paidós.

(1997): ¿Podremos vivir juntos?, México, Fondo de Cultura Económica.

Verdú, V. (2005): Yo y tú, objetos de lujo, Barcelona, Debate. (2003): El estilo del mundo, Barcelona, Anagrama. 